\title{
La caducidad de la Resolución de Calificación Ambiental
}

\author{
Javier Herrera Valverde* \\ Samuel Ruiz-Tagle Gutiérrez**
}

\begin{abstract}
RESUMEN
El presente artículo estudia la conceptualización de la figura de la caducidad en el derecho civil y administrativo, así como su recepción por la legislación y jurisprudencia judicial y administrativa chilena, con el objeto de efectuar un análisis crítico de la configuración legal y reglamentaria de la misma figura en materia medioambiental. De acuerdo con ello, este trabajo da cuenta de las principales deficiencias normativas que presenta la caducidad de una Resolución de Calificación Ambiental, desde el punto de vista de sus supuestos de procedencia, órgano competente para su declaración, procedimiento aplicable, recursos administrativos y jurisdiccionales procedentes y los efectos que genera su declaración. Desde luego, se propone también una solución interpretativa a las problemáticas detectadas.
\end{abstract}

Caducidad - Resoluciones de Calificación Ambiental - Servicio de Evaluación Ambiental

\section{The Expiry of the Environmental Permit}

\begin{abstract}
This article studies the conceptualization of the expiration figure in the civil and administrative law, as its reception by the Chilean judicial and administrative jurisprudence, with the object of carrying on a critic analysis of the legal and regulatory configuration of the same among environmental matters. According to it, this piece of work realizes the main normative deficiencies that the expiration of an Environmental Qualification Resolution presents, from the point of view of its requirements of provenance, competent organism for its declaration, applicable procedure, administrative and jurisdictional recourses proceeding and the effects that its declaration generates. Thereby, an interpretative solution to the detected problematic is proposed.
\end{abstract}

Expiry - Environmental Permit - Environmental Assessment Agency

* Abogado, Licenciado en Derecho de la Pontificia Universidad Católica de Chile, Instructor Asociado de Derecho Administrativo en la misma Universidad. Correo electrónico: jnherrer@uc.cl.

** Abogado, Licenciado en Ciencias Jurídicas y Sociales de la Universidad de Chile, Ayudante de Derecho Administrativo en la misma Universidad. Correo electrónico: sruiztagle@cubillosevans.cl.

Artículo recibido el 31 de marzo de 2014 y aceptado para su publicación por el Comité Editorial el 28 de mayo de 2014. 


\section{CONSIDERACIONES PREVIAS}

$\mathrm{L}$ a Ley $\mathrm{N}^{\circ}$ 20.417, que crea el Ministerio, el Servicio de Evaluación Ambiental y la Superintendencia del Medio Ambiente, publicada en el Diario Oficial el 26 de enero de 2010, introdujo en nuestro ordenamiento jurídico ambiental la figura de la "caducidad" de las Resoluciones de Calificación Ambiental (RCA).

Dicha caducidad, de acuerdo con la ley, opera cuando hubieren transcurrido más de cinco años sin que se haya iniciado la ejecución del proyecto o actividad autorizado, en tanto aquello le conste fehacientemente a la autoridad ambiental, y en los demás casos en que existan infracciones comprobadas, que revistan determinados criterios que contempla la ley.

Sin embargo, la Ley No 20.417 no reguló de un modo orgánico la aplicación de tal figura, limitándose a señalar únicamente algunos supuestos básicos para su procedencia, existiendo por consiguiente un conjunto de problemáticas y deficiencias normativas de compleja solución jurídico-interpretativa, y que naturalmente determinan el modo en que dicha figura debe operar.

Por lo anterior, si bien el establecimiento de la figura en comento constituyó un acierto legislativo, su regulación adoleció de una falta de densidad normativa evidente, particularmente en lo que dice relación con el órgano competente para declararla, sus requisitos y procedimiento. Trataremos, en lo posible, de hacernos cargo de tales problemas normativos y, con ello, iluminar en parte este sombrío aspecto de Ley $\mathrm{N}^{\circ} 20.417$.

\section{Panorama general de la Caducidad en el Derecho Civil Y ADMINISTRATIVO Y SU RECEPCIÓN EN LA LEGISLACIÓN Y JURISPRUDENCIA CHILENA}

Como lo ha señalado la literatura especializada, no es posible identificar una definición única del concepto de caducidad, que posea elementos comunes que se puedan observar cada vez que una norma jurídica emplea tal vocablo. Lo anterior se debe a que la caducidad, en cuanto concepto o institución, posee un carácter polifacético o "anfibológico"1, el cual depende de la óptica jurídica desde la cual se le analice.

A su vez, que la caducidad posea tal variedad de significados se traduce en que las características y efectos que se le atribuyan a la misma serán también distintos en cada una de las áreas del derecho en que se la utilice. Por ello, antes de estudiar la regulación de la caducidad en materia ambiental, resulta necesario analizar los principales aspectos que han definido a esta institución en el Derecho civil, en cuanto derecho general

1 Tardío Pato, J.A., "Caducidad del procedimiento administrativo", en Diccionario de Derecho Administrativo (Dir. Santiago Muñoz Machado), Iustel, Tomo I, Madrid, 2005, p. 358. En el mismo sentido, véase Vergara Blanco, A., "Nota sobre la caducidad como fuente de extinción de derechos y del decaimiento del procedimiento administrativo", en Actas XXXIV Jornadas de Derecho Público Pontificia Universidad Católica de Chile, Santiago, 2004, p. 567. 
y supletorio, y en el Derecho administrativo, en la medida que el Derecho ambiental integra la denominada parte especial de este último ${ }^{2}$.

\section{La caducidad en el Derecho civil}

En el Derecho civil, los autores han abordado la caducidad al estudiar los efectos del transcurso del tiempo en las relaciones jurídicas de naturaleza privada ${ }^{3}$. Basados en tal enfoque, de acuerdo a Abeliuk, estaremos en presencia de la caducidad cada vez que la ley establezca un plazo para ejercitar un derecho o ejecutar un acto, sin que sea posible ejercer tal derecho o ejecutar tal acto una vez vencido dicho plazo ${ }^{4}$. En la misma línea, aunque de un modo más amplio, Alessandri y Somarriva han sostenido que existirá caducidad "cuando la ley o la voluntad del hombre prefija un plazo para el ejercicio de un derecho (realización de un hecho cualquiera, o ejercicio de una acción judicial), de tal modo que, transcurrido el término, no puede ya el interesado verificar el acto o ejercitar la acción"5.

Ahora bien, para los iusprivatistas, el énfasis o la preocupación no ha sido estudiar las particularidades y características de la caducidad en cuanto institución, sino que el interés se ha radicado en destacar sus diferencias con otras figuras afines y de mayor relevancia para los civilistas, como la prescripción extintiva, la que, como sabemos, es definida como "un modo de extinguir los derechos y acciones ajenos, por no haberlos ejercitado el acreedor o titular de ellos durante cierto tiempo, concurriendo los demás requisitos legales" 6 . Una simple mirada a esta última definición nos permite constatar la cercanía existente entre caducidad y prescripción, en cuanto ambas están ligadas a los efectos del tiempo en las relaciones o situaciones jurídicas.

Sin embargo, no obstante la afinidad entre ambas figuras, es posible observar una clara distinción conceptual entre ellas. Así, mientras la prescripción busca extinguir un derecho que se supone abandonado por no haberlo ejercitado su titular en un tiempo determinado, la caducidad persigue establecer un plazo perentorio dentro del cual puede ejercitarse un derecho. Dicho de otra manera, mientras la prescripción considera las razones subjetivas del titular del derecho para determinar la extinción del mismo

${ }^{2}$ En ese sentido, véase Wahl, R., Los Últimos Cincuenta Años de Derecho Administrativo Alemán, Marcial Pons, Madrid, 2013, pp. 70 y ss. Igualmente, véase Schimdt-Assman, E., La Teoría General del Derecho Administrativo como Sistema, Marcial Pons, Barcelona, 2003, pp. 127 y ss. En el derecho nacional, véase Bermúdez Soto, J., Fundamentos de Derecho Ambiental, Ediciones Universitarias de Valparaíso, Valparaíso, 2007, p. 35, para quien es en el Derecho público, y específicamente en el Derecho administrativo, donde el Derecho ambiental encuentra su centro de gravedad.

${ }^{3}$ Un detallado estudio sobre la caducidad en el derecho civil, que analiza desde la etimología del término, su origen histórico, su recepción en el derecho comparado, su objeto y fundamento, entre otros aspectos, puede consultarse en Gómez Corraliza, B., La Caducidad, Editorial Montecorvo S.A., Madrid, 1990, 655 p.

${ }^{4}$ Abeliuk Manasevich, R., Las Obligaciones, Tomo II, Editorial Jurídica de Chile, Santiago, 2001, p. 1075.

${ }^{5}$ Alessandri, A. y Somarriva, M., Curso de Derecho Civil, Tomo I, Volumen II: Parte General y Las Personas, Editorial Nascimiento, Santiago, 1962, p. 106.

${ }^{6}$ Según lo señala el artículo 2492 del Código Civil. 
-inactividad, negligencia-, la caducidad atiende única y exclusivamente al transcurso objetivo de un plazo específico, sin importar las razones por las cuales el respectivo derecho haya sido ejercido o no por su titular dentro de tal plazo ${ }^{7}$. Por lo tanto, si bien la prescripción y la caducidad se asemejan en cuanto ambas extinguen un derecho y su respectiva acción, la diferencia principal estriba en las causas por las cuales el legislador establece una u otra institución: sancionar la inactividad (negligencia) o establecer un plazo para el ejercicio perentorio de un derecho ${ }^{8}$.

Hechas las precisiones anteriores entre ambos conceptos, veamos ahora cuál es la importancia de determinar cuándo estamos en presencia de una u otra figura: a la prescripción se aplican las causales de suspensión e interrupción, lo que no sucede con la caducidad, la que no puede suspenderse ni interrumpirse por causa alguna. La razón de lo anterior radica en el fundamento de una u otra: mientras la prescripción puede suspenderse o interrumpirse por haber cesado la inactividad del titular del derecho (aspecto subjetivo), en la caducidad ninguna causa podrá soslayar el no ejercicio del derecho en el plazo prefijado (aspecto objetivo).

Finalmente, aun cuando la doctrina civil ha intentado clarificar las diferencias entre ambos conceptos, que las hay, existen múltiples situaciones en que la ley establece supuestos bajo los cuales simplemente se extinguen ciertos derechos y acciones, sin que se señale si se trata de prescripción extintiva o caducidad. Frente a tales situaciones, será tarea del intérprete determinar, caso a caso, si el legislador se ha referido a la prescripción extintiva o a la caducidad.

\section{La caducidad en el Derecho administrativo}

A diferencia de lo que ocurre en Derecho civil, en donde a pesar de las distintas definiciones existe un énfasis común -centrado en los efectos del transcurso del tiempo-, en el Derecho administrativo la cuestión es algo distinta, pues en él podemos observar con mayor fuerza el carácter "anfibológico" de este concepto. Esa diversidad conceptual, en el Derecho administrativo responde a la "ductilidad" de las normas e instituciones jurídico-administrativas existentes, debiendo operar la caducidad en función de cada una de las categorías respecto de las cuales se aplique?.

En el Derecho comparado, la literatura ha diferenciado distintos tipos de caducidad: (i) caducidad de acciones, de pretensiones, de derechos y de potestades;

${ }^{7}$ Alessandri, A. y Somarriva, M., Op. Cit. (n. 5), p. 106.

${ }^{8}$ Si bien a nuestro juicio aquella es la más importante diferencia, Abeliuk sostiene que, además, es posible destacar las siguientes distinciones: (i) en la caducidad prima el interés del legislador de estabilizar rápidamente una situación jurídica, mientras que la prescripción atiende a varios intereses diversos, entre ellos la seguridad jurídica; (ii) la caducidad puede y debe ser declarada de oficio, mientras que la prescripción debe ser alegada; (iii) la prescripción extintiva supone un vínculo jurídico previo, mientras que la caducidad no lo requiere. Véase Abeliuk, R., Op. Cit. (n. 4), p. 1076.

9 Rodríguez Arana, J., "Reflexiones Sobre la Caducidad en el Derecho Público", en Revista Aragonesa de Administración Pública, No 5, Zaragoza, 1994, p. 346. 
(ii) caducidad-preclusión de trámites procedimentales; (iii) caducidad-perención del procedimiento administrativo ${ }^{10}$.

Así, en primer lugar, existirá caducidad de acción o de pretensión cuando ha transcurrido un plazo para interponer recursos administrativos o contencioso-administrativos, sin que se haya efectuado tal actuación ${ }^{11}$. También la caducidad de derechos se generará en aquellos casos en que un derecho nazca a la vida jurídica sujeto a un plazo determinado, o en que se prevé como sanción ante el incumplimiento de obligaciones o condiciones impuestas por el ordenamiento al titular de un acto ${ }^{12}$. Finalmente, se generará una caducidad de potestades en aquellos casos en que la ley establece un plazo determinado dentro del cual un organismo administrativo puede ejercer una potestad, de manera que transcurrido dicho plazo no será posible que aquella sea ejercida ${ }^{13}$.

En segundo lugar, en el Derecho comparado la doctrina distingue la caducidad de trámites procedimentales, esta consiste en aquellos supuestos en que la legislación establece un breve plazo para que una parte efectúe ciertos actos, sin que puedan realizarse tales actos una vez cumplido dicho plazo.

En tercer lugar, encontramos la denominada caducidad del procedimiento o "perención”, que es aquella en que el procedimiento administrativo termina de manera anormal, por haberse paralizado por causa imputable al interesado, y sin que se haya reanudado dentro del plazo legal, o por no haber dictado la administración resolución expresa o no haber notificado la respectiva resolución dentro del plazo máximo contemplado para tal efecto ${ }^{14}$.

Por su parte, en el Derecho administrativo nacional, Carmona ha incluido a la caducidad dentro de los actos de gravamen o restrictivos, particularmente dentro de los actos extintivos, que define como aquellos cuyo efecto es extinguir un derecho o una relación jurídica, bien actuando directamente sobre estos o sobre el acto origen del

10 Tardío Pato, J.A., Op. Cit. (n. 1), p. 358. Nótese que esta clasificación se efectúa por el autor a la luz de la legislación española, no obstante ello puede ser utilizada, al menos conceptualmente, en aquellos casos en que sean compatibles con la nuestra.

${ }^{11}$ Desde el punto de vista de los recursos administrativos, véase García de Enterría, E. y Fernández, T., Curso de Derecho Administrativo. II, Civitas, Duodécima edición, Pamplona, 2011, p. 551. En relación con los recursos contencioso-administrativos, véase Parejo Alfonso, L., Lecciones de Derecho Administrativo, Editorial Tirant lo Blanch, Quinta edición revisada y actualizada, Valencia, 2012, p. 668.

12 Tardío Pato, J.A., Op. Cit. (n. 1), p. 358. Para un mayor estudio de la caducidad-sanción, que por algunos ha sido elevada a una clase de caducidad independiente, véase: Caballero Sánchez, R. "Procedimiento Sancionador: Caducidad”, en Diccionario de Sanciones Administrativas (Dir. Blanca Lozano Cutanda), Iustel, primera edición, Madrid, 2010, pp. 799-826.

13 Tardío Pato, J.A., Op. Cit. (n. 1), p. 358.

${ }^{14}$ Santamaría Pastor, J.A., Principios de Derecho Administrativo General, Iustel, Madrid, Tomo II, 2009, pp. 99 y 100. Igualmente, véase Tardío Pato, J.A., "Consideraciones Sobre la Caducidad del Procedimiento Administrativo", en Revista de Estudios de la Administración Local y Autonómica, No 298-299, 2005, p. 18, y De Diego, L.A., Prescripción y Caducidad en el Derecho Administrativo Sancionador, Bosch, Barcelona, 2005, p. 203. Finalmente, un mayor estudio sobre la perención como modo de finalización del procedimiento administrativo, véase en González Pérez, J., y González Navarro, F., Comentarios a la Ley de Régimen Jurídico de las Administraciones Públicas y Procedimiento Administrativo Común, Civitas, Madrid, 2004, pp. 2231 y siguientes. 
derecho o relación ${ }^{15}$. A su vez, Bermúdez ha señalado que la caducidad se presenta como una forma anormal de extinción del acto administrativo que opera en aquellos casos en que el acto contiene una modalidad, ya sea un plazo, condición resolutoria u otra, que de cumplirse conlleva la desaparición del acto administrativo ${ }^{16}$. Una visión distinta a las anteriores es la de Vergara, quien ha conceptualizado esta figura en el plano de las sanciones administrativas, y para el cual la caducidad opera como una sanción que extingue un derecho ya nacido, por cumplirse una causal legal de incumplimiento de obligaciones $^{17}$.

Como puede observarse, mientras en la doctrina nacional la caducidad ha sido conceptualizada como una forma de extinción de los actos administrativos o como sanción de igual naturaleza, en el Derecho comparado la caducidad es entendida de manera más genérica, aplicándose no solo respecto de actos, sino que también de acciones, derechos, potestades, trámites y procedimientos.

Ahora bien, doctrinariamente no es del todo claro que la caducidad pueda conceptualizarse, en términos generales, como una forma de extinción de los actos administrativos, pues en numerosas ocasiones esta institución opera únicamente en el plano de la eficacia de los actos administrativos, generando la cesación de los efectos del mismo, pero sin alterar su existencia. Incluso, parte de la literatura, extremando el argumento, ha sostenido que la caducidad en sede administrativa opera siempre en el plano de la eficacia del negocio jurídico, como cláusula accesoria conectada al incumplimiento de obligaciones esenciales por parte de su titular ${ }^{18}$.

Pues bien, más allá de las discusiones doctrinarias, y para efectos de avanzar en nuestro análisis, sostenemos que tanto la forma en que operará la caducidad como también su conceptualización dependerán de la configuración normativa que a su respecto se establezca, sin que puedan determinarse a priori los alcances de su aplicación, toda vez que, como vimos, la caducidad no siempre implicará la muerte o desaparición del acto, sino que este podrá mantenerse intacto y existente, aunque estéril o infructuoso por no generar sus efectos propios.

\section{Recepción de la caducidad en la legislación y jurisprudencia judicial y administrativa}

La caducidad ha sido ampliamente reconocida por nuestra legislación, la que en los más diversos ámbitos ha establecido tal figura como modo de extinguir los derechos

${ }^{15}$ Carmona Santander, C., Las Formas de Actuación de la Administración. El Acto Administrativo, Facultad de Derecho de la Universidad de Chile, Santiago, 2005, p. 49 y 50.

${ }^{16}$ Bermúdez Soto, J., Derecho Administrativo General, Legal Publishing Chile, Santiago, 2011, p. 141.

${ }^{17}$ Vergara Blanco, A., Op. Cit. (n. 1), p. 568. En el mismo sentido, véase Soto Kloss, E. "Prescripción extintiva de derechos de los administrados y cumplimiento de las obligaciones legales impuestas a la Administración”, en Revista Chilena de Derecho, Vol. 11, № 2-3, 1984, p. 508, para quien la caducidad es la "pérdida de un derecho (o del ejercicio de un derecho, en el caso de los actos autorizatorios) por el no cumplimiento de las exigencias o requisitos impuestos por la ley para su ejercicio, caducidad que no es sino una medida/sanción (frente a una carga no cumplida por el beneficiario)".

18 Rodríguez Arana, J., Op. Cit. (n. 9), p. 347. 
otorgados por un acto administrativo válido y eficaz, por el incumplimiento de obligaciones legal o reglamentariamente establecidas (caducidad-sanción). Así, por ejemplo, se ha establecido en la Ley General de Urbanismo y Construcciones y en su Ordenanza General, la Ley General de Pesca y Acuicultura, en la Ley General de Bancos, en materia de concesiones marítimas, en la Ley N 18.696 que Establece Normas Sobre Transporte de Pasajeros, en el D.L. N $\mathrm{N}^{\circ}$ 1.939, de 1977, Sobre Adquisición, Administración y Disposición de Bienes del Estado, entre otras ${ }^{19}$.

Por su parte, la jurisprudencia judicial ha reconocido a la caducidad de diversas formas, ya sea como forma de extinción de los actos administrativos, señalando que en derecho administrativo los actos administrativos y sus efectos pueden extinguirse o dejarse sin efecto por determinadas causales, entre las que se encuentran la revocación, la invalidación, la caducidad y la nulidad... ${ }^{20}$, o como forma de sanción extintiva de un derecho producto de un incumplimiento de una obligación, afirmando que la caducidad, esto es, la extinción de un derecho por el incumplimiento del interesado, dentro del término estipulado, de las obligaciones que se le imponen expresamente por la ley pertinente ${ }^{21}$. Por último, nótese que la llamada caducidad del procedimiento o perención corresponde a lo que la jurisprudencia judicial chilena ha identificado -erróneamente- como decaimiento del procedimiento administrativo en el marco de los procesos administrativos sancionatorios ${ }^{22}$.

${ }^{19}$ La Ley General de Urbanismo y Construcciones, establecida mediante D.F.L. No 458 de 1976, reconoce la caducidad en materia de patentes (artículo 58), declaratorias de utilidad pública (artículo 59), permisos (artículo 120); la Ley General de Pesca y Acuicultura contempla en su Título XI todo un apartado sobre Caducidades en el que se contiene la regulación asociada a la caducidad de: (i) las concesiones y autorizaciones de acuicultura (artículo 106) y (ii) las áreas de manejo y explotación de los recursos bentónicos (artículo 108); la Ley N ${ }^{\circ} 18.696$ que Establece Normas Sobre Transporte de Pasajeros, se refiere a la caducidad de concesiones en su artículo 2; la Ley General de Bancos en su artículo 156 establece un sistema de caducidad de depósitos y captaciones de cinco años contado desde que en la respectiva cuenta no se haya hecho movimiento alguno y se hubieren efectuado las listas y publicaciones requeridas por la norma; el D.F.L. No 340, de 1960, del Ministerio de Hacienda, sobre Concesiones Marítimas establece en su artículo $7^{\circ}$ las causales de caducidad de la concesión, el procedimiento y recursos administrativos respectivos; y, finalmente, el D.L. N ${ }^{\circ}$ 1.939, de 1997, que norma sobre adquisición, administración y disposición de bienes del Estado, establece en su artículo 80 el derecho a reclamo del arrendatario de inmuebles fiscales, respecto del acto administrativo que declara la caducidad de sus derechos.

${ }^{20}$ Sentencia de fecha 10 de agosto de 2009 de la Iltma. Corte de Apelaciones de Temuco, en causa Rol $\mathrm{N}^{\circ}$ 830-2009, confirmada por la sentencia de fecha 16 de septiembre de 2009 de la Excma. Corte Suprema, en causa Rol No 6021-2009.

${ }^{21}$ Sentencia de fecha 6 de octubre de 2010 de la Excma. Corte Suprema, en causa Rol No 5666-2010.

${ }^{22} \mathrm{Si}$ bien al conocer recursos de reclamación en contra de sanciones administrativas la Excma. Corte Suprema ha sostenido la existencia de un decaimiento del procedimiento administrativo, en doctrina, el decaimiento administrativo corresponde a una forma de extinción del acto administrativo propiamente tal, que se genera al desaparecer los presupuestos fácticos o jurídicos que se tuvieron a la vista al momento de dictar el acto. Por lo tanto, el decaimiento opera respecto del acto, y no del procedimiento. Al respecto, véase Olguín Juárez, H., Extinción de los Actos Administrativos. Revocación, Invalidación y Decaimiento, Editorial Jurídica de Chile, Santiago, 1961, p. 267 y ss. Igualmente, Cordero Vega, L., "El Decaimiento del Procedimiento Administrativo Sancionador", en Comentarios a las Sentencias de la Corte Suprema del año 2010, Anuario de Derecho Público, Universidad Diego Portales, Santiago, 2011, pp. 243-255. 
A su vez, resulta útil analizar cómo ha sido entendida la caducidad en la jurisprudencia administrativa de la Contraloría General de la República, en la medida que sus dictámenes resultan obligatorios para todos los Órganos de la Administración del Estado, no pudiendo estos últimos sino acatarlos ${ }^{23}$.

Pues bien, la Contraloría ha reconocido la caducidad de permisos, nombramientos, patentes municipales, concesiones, entre otros, en la medida que tal figura sea establecida en la legislación sectorial respectiva. De la misma manera, la jurisprudencia ha reconocido la figura de la caducidad en cuanto sanción administrativa, señalando que los decretos y resoluciones se pueden dejar sin efecto por un acto administrativo posterior de contrario imperio... por el incumplimiento de una obligación prevista por la ley o por el propio acto cuya sanción específica es la extinción del mismo... ${ }^{24}$.

Ahora bien, la Contraloría no ha construido un concepto general de caducidad, sino que se ha limitado a reconocer los casos en que la legislación emplea tal concepto, ya sea como extinción de un acto administrativo o como sanción en casos de incumplimiento, lo que a su vez coincide con la forma en que la doctrina chilena ha entendido la caducidad.

Sin perjuicio de lo anterior, cuando se trata de la aplicación de plazos que la ley establece para el ejercicio de acciones o derechos de los administrados o de potestades de la Administración, la jurisprudencia de la Contraloría ha seguido una antigua doctrina, aplicando en el ámbito administrativo las distinciones efectuadas por la doctrina civilista. Así, desde al menos 1966, la Contraloría ha señalado que la caducidad extingue además de la acción para reclamar un determinado beneficio, el derecho mismo a este; ...opera ipso facto $y$ de pleno derecho, por el solo transcurso del plazo legal prefijado, y no necesita que sea previamente declarada, el plazo es fatal e irrenunciable, y no admite interrupciones ni suspensiones de ninguna clase $^{25}$. Esta forma de entender la caducidad, en el marco de potestades de organismos públicos, también ha sido aplicada por la Contraloría al analizar la naturaleza del plazo de dos años para ejercer la potestad invalidatoria establecida por la Ley $\mathrm{N}^{\circ} 19.880$, respecto de ello ha sostenido que es de caducidad y no de prescripción, de modo que no puede interrumpirse ni suspenderse por la interposición de reclamos durante su vigencia ${ }^{26}$.

En definitiva, la jurisprudencia judicial y administrativa, al igual que la literatura nacional y comparada, no ha desarrollado un concepto general de caducidad que sea aplicable, ya sea en el ámbito del derecho civil o administrativo, sin perjuicio del criterio invariable referido a la aplicabilidad de la concepción civilista en materia de plazos de caducidad para el ejercicio de derechos o potestades.

${ }^{23}$ Ello, conforme a lo dispuesto por el artículo $9^{\circ}$ inciso final de la Ley $\mathrm{N}^{\circ} 10.336$, de 1952, de Organización y Atribuciones de la Contraloría General de la República. Lo anterior es de toda importancia para nuestro estudio, ya que los organismos administrativos con competencia para aplicar la caducidad en materia ambiental deberán, naturalmente, cumplir con los criterios interpretativos que sobre la materia ha establecido el ente contralor.

${ }^{24}$ Dictamen $\mathrm{N}^{\circ} 89.271$, de 22 de noviembre de 1966.

${ }^{25}$ Dictamen $\mathrm{N}^{\circ} 91.117$, de 25 de noviembre de 1966, $\mathrm{N}^{\circ} 82.577$, de 23 de diciembre de 1969, $\mathrm{N}^{\circ} 7.522$, de 2 de febrero de 1970, $\mathrm{N}^{\circ} 52.014$, de 10 de agosto de $1970, \mathrm{~N}^{\circ} 72.938$, de 19 de septiembre de 1973 .

${ }^{26}$ Dictamen $\mathrm{N}^{\mathrm{o}} 10.449$, de 11 de febrero de 2014. 


\section{LA CADUCIDAD DE LA RCA EN EL DERECHO AMBIENTAL CHILENO}

\section{Recepción de la caducidad administrativa en la Ley $N^{0} 19.300$}

La Ley $\mathrm{N}^{\circ} 20.417$ estableció la figura de la caducidad administrativa bajo dos modalidades, que para estos efectos denominaremos caducidad general y caducidad sanción ${ }^{27}$.

La caducidad general está contenida en el número 31 del artículo primero de la Ley $\mathrm{N}^{\circ}$ 20.417, que modificó la Ley $\mathrm{N}^{\circ} 19.300$ al establecer un nuevo artículo 25 ter, el cual actualmente dispone que La resolución que califique favorablemente un proyecto o actividad caducará cuando bubieren transcurrido más de cinco años sin que se haya iniciado la ejecución del proyecto o actividad autorizada, contado desde su notificación. El Reglamento deberá precisar las gestiones, actos o faenas mínimas que, según el tipo de proyecto o actividad, permitirán constatar el inicio de la ejecución del mismo. El supuesto fundamental para la procedencia de esta modalidad de caducidad descansa en que no se haya iniciado la ejecución del proyecto, mediante gestiones, actos o faenas mínimas, durante el término de cinco años.

Por su parte, la caducidad sanción se encuentra contenida en el artículo segundo de la Ley $N^{\circ}$ 20.417, que establece la Ley Orgánica de la Superintendencia del Medio Ambiente (Ley Orgánica de la SMA o LOSMA), y cuyo artículo $3^{\circ}$ letra 1) otorga a tal Superintendencia (SMA) la facultad para requerir del Servicio de Evaluación Ambiental (SEA) la caducidad de una RCA no solo cuando han transcurrido más de 5 años sin que se haya iniciado la ejecución del proyecto autorizado, sino también en los demás casos en que, atendida la magnitud, gravedad, reiteración o efectos de las infracciones comprobadas durante su ejecución ofuncionamiento, resulte procedente. En este segundo caso, el legislador únicamente se limitó a establecer un supuesto de caducidad fundado en la existencia de infracciones ambientales que, comprobadas, deben estar revestidas de criterios de gravedad, trascendencia y reiteración. Sin embargo, a diferencia de lo que ocurre con la caducidad general, cuya aplicación está dada por la circunstancia objetiva del transcurso del plazo, la determinación de aquellas infracciones comprobadas es un asunto que presenta una mayor problemática, pues su verificación queda entregada completamente a la autoridad ambiental, existiendo un mayor margen de "discrecionalidad jurídica instrumental”, en la terminología de Desdentado, visible al momento de aplicar los criterios o conceptos jurídicos indeterminados de "magnitud", "gravedad", "reiteración" o "efectos" 28.

A nuestro juicio, el establecimiento de la caducidad general constituye un acierto de la reforma a la institucionalidad ambiental, toda vez que los proyectos y actividades son evaluados y aprobados en un contexto ambiental y social determinado, el que

${ }^{27}$ Si bien podría aducirse que ambas modalidades obedecen a una suerte de sanción al titular de un proyecto o actividad, para efectos pedagógicos hemos adoptado dicha clasificación, considerando que la denominada caducidad sanción, como se señalará más adelante, debe ser precedida del respectivo procedimiento sancionatorio iniciado por la SMA, cuestión que no ocurre con la caducidad general.

${ }^{28}$ Desdentado Daroca, E., "Discrecionalidad Administrativa en la Imposición de Sanciones", en Diccionario de Derecho Administrativo (Dir. Blanca Lozano Cutanda), Op. cit. (n. 12), p. 345. 
lógicamente varía con el transcurso del tiempo. Siendo ello así, el hecho de ejecutar un proyecto años después de su evaluación implicaría un desfase entre el Estado y características del ecosistema considerado al momento de la evaluación y aquel existente al momento de ejecutarse el proyecto o actividad, perdiendo su objetivo la evaluación ambiental realizada.

A diferencia de lo que ocurre con la caducidad general, no se encuentra del todo clara la utilidad y necesidad de establecer una figura de caducidad sanción, ya que en el caso de cumplirse los supuestos o requisitos que la hacen procedente, los mismos podrían ser abordados mediante otras técnicas administrativas contempladas por la misma ley, como el inicio de un proceso de sanción y la aplicación posterior de la medida de revocación de RCA, que en términos prácticos genera el mismo efecto jurídico atribuido a la caducidad, al actuar como un modo de extinción del acto administrativo autorizatorio del proyecto o actividad.

Pues bien, independiente de lo anterior, nuestra legislación contempla actualmente una figura de caducidad ambiental, bajo dos supuestos, cada uno de ellos con sus propios requisitos y condiciones. En el caso de la caducidad general, esta actúa como sanción impropia, generando la extinción del título habilitante adquirido, como consecuencia del incumplimiento de las condiciones de ejercicio del mismo ${ }^{29}$, condición que en este caso consiste en iniciar la ejecución del proyecto dentro del plazo legal establecido. A su vez, en el supuesto de caducidad sanción, esta se configura derechamente como una sanción administrativa asimilable en sus efectos extintivos a la revocación de la RCA, que implícitamente modifica el catálogo de sanciones contemplado en el artículo 38 de la Ley Orgánica de la SMA. Sobre este último punto se debe considerar especialmente que, como ha señalado Laguna de Paz, en muchas ocasiones "el legislación utiliza los términos revocación y caducidad -o incluso, suspensión definitiva- de forma indistinta" 30 .

\section{Principales problemáticas y deficiencias normativas en la configuración legal y reglamentaria de la caducidad en materia ambiental}

\subsection{Supuestos de procedencia}

En el caso de la caducidad general, los supuestos para su aplicación son los siguientes: (i) que se haya constatado por la SMA la omisión del responsable del proyecto en iniciar la ejecución de la actividad autorizada; (ii) que hayan transcurrido cinco años desde la notificación de la RCA sin que se hayan ejecutado obras mínimas que acrediten el inicio de dicha ejecución.

Para acreditar tales supuestos, la Ley No 19.300 estableció que vía Reglamento se precisarían las gestiones, actos o faenas mínimas que, según el tipo de proyecto o actividad,

29 Caballero Sánchez, R. "Procedimiento Sancionador: Caducidad", en Diccionario de Sanciones Administrativas (Dir. Blanca Lozano Cutanda), Op. cit. (n. 12), p. 799.

${ }^{30}$ Laguna de Paz, J., La Autorización Administrativa, Editorial Aranzadi, Navarra, 2006, p. 333. 
permitirán constatar el inicio de la ejecución. Sin embargo, el recientemente publicado DS N ${ }^{\circ} 40 / 2013$, del Ministerio del Medio Ambiente, que estableció el nuevo Reglamento del Sistema de Evaluación de Impacto Ambiental (Reglamento del SEIA), no reguló de forma pormenorizada tales gestiones mínimas, lo que constituye un primer problema o deficiencia normativa, reenviando la facultad de definir y determinar de tales faenas mínimas a los titulares de proyectos, según se observa en el artículo 16 de ese cuerpo reglamentario. Dicho reenvío resulta al menos cuestionable, toda vez que la ley mandató a la potestad reglamentaria de ejecución tal determinación, sin dejar espacio para su entrega a los particulares.

No obstante no haberse pormenorizado las gestiones, actos o faenas mínimas, atendido el tipo de proyecto o actividad, el artículo 73 del Reglamento del SEIA señaló que se entenderá que se ha dado inicio a la ejecución del proyecto o actividad, cuando se realice la ejecución de gestiones, actos u obras, de modo sistemático, ininterrumpido y permanente destinado al desarrollo de la etapa de construcción del proyecto o actividad. De acuerdo con ello, para evitar la caducidad de una RCA el responsable del proyecto debe acreditar fehacientemente, de un modo sistemático, ininterrumpido y permanente, la voluntad efectiva de ejecutar su proyecto.

Finalmente, sin perjuicio que no se ha determinado qué debe entenderse por inicio de ejecución, resulta útil recordar que la Contraloría General de la República, al momento de definir qué debe entenderse por "ejecución" o "modificación" de proyecto o actividad a que alude el artículo 8 de la Ley $\mathrm{N}^{\circ}$ 19.300, ha señalado que la "ejecución” está constituida por la realización de actos materiales ${ }^{31}$, de manera que el "inicio de la ejecución" naturalmente también implica la realización de actos materiales que den cuenta de la voluntad real de llevar adelante el proyecto aprobado. Por ello, el mero otorgamiento de permisos necesarios para la construcción o desarrollo del proyecto o actividad no es suficiente para acreditar el inicio de la ejecución del mismo.

Un segundo problema que plantea la determinación de los supuestos de aplicabilidad de la caducidad general está dado por el cómputo del plazo, esto es, si el mismo puede o no interrumpirse o suspenderse por alguna causa, ya que las RCA de los proyectos o actividades son muchas veces impugnadas administrativa y jurisdiccionalmente por una serie de recursos administrativos y contencioso-administrativos ${ }^{32}$.

Al respecto, como hemos señalado, la Contraloría ha estimado que los plazos de caducidad no se interrumpen ni se suspenden por causa o recurso alguno, criterio que puede ser aplicado, por regla general, respecto de la caducidad que analizamos, sobre todo

${ }^{31}$ Véanse los Dictámenes $\mathrm{N}^{\mathrm{o}} 38.762$, de 10 de octubre de 2000, No 29.143, de 21 de junio de 2006 y N $\mathrm{N}^{\circ}$ 12.659, de 20 de marzo de 2008, de la Contraloría General de la República.

${ }^{32}$ Al respecto, véase De la Fuente Castro, O., El control judicial de la resolución de calificación ambiental, LegalPublishing, Santiago, 2012, p. 95 y siguientes. Para conocer un panorama general sobre la materia, véase Bermúdez Soto, J., “Administración y Jurisdicción Ambiental: La institucionalidad ambiental frente al nuevo contencioso-administrativo”, en La Nulidad de los Actos Administrativos en el Derecho Chileno. IX Jornadas de Derecho Administrativo, Juan Carlos Ferrada Bórquez (Coordinador), Editorial Thomson Reuters, Chile, pp. 485-511. 
considerando que la interposición de los recursos administrativos no suspenderá la ejecución del acto impugnado, según lo dispuesto en el artículo 57 de la Ley $\mathrm{N}^{\circ}$ 19.880. Sin embargo, una situación distinta se presenta en el caso que se ejerciten acciones jurisdiccionales, pues con la ocasión del ejercicio de algunas de estas acciones, particularmente la acción de protección, es posible que se suspendan los efectos del acto autorizatorio, mediante la correspondiente orden de no innovar ${ }^{33}$.

En dicho caso, ¿se suspende el cómputo del plazo de caducidad en razón de la orden de no innovar decretada? La cuestión no es del todo clara, ya que podría cuestionarse si por la vía de una resolución judicial puede ordenarse la suspensión de un plazo legal, que no establece excepciones para su cómputo. En nuestra opinión, creemos que dicha suspensión, otorgada judicialmente, por una Corte o el Tribunal Ambiental, se extiende a los plazos para la declaración de caducidad. Si aquello no fuera así, el responsable del proyecto se vería afectado por una decisión que naturalmente depende de un tercero, el juez, quien conocerá de la legalidad o mérito de la aprobación ambiental en un plazo que no depende de la voluntad del titular del proyecto o actividad.

Aclaradas las problemáticas principales que presenta la aplicación de la caducidad general, veamos ahora cuáles son los supuestos de la que hemos denominado caducidad sanción. Al respecto, el artículo $3^{\circ}$ letra l) de la Ley Orgánica de la SMA establece la facultad de ese órgano de "requerir" al SEA la caducidad en los demás casos, cuando hubieren infracciones comprobadas que sean revestidas de criterios de magnitud, gravedad, reiteración o efectos. El establecimiento de este supuesto, creemos, es discutible desde una doble perspectiva.

En primer lugar, es discutible respecto de su utilidad, toda vez que dicha caducidad está construida sobre la base de una hipótesis de incumplimiento previo de las normas, condiciones y medidas de una RCA. Entonces, si hay una infracción comprobada, que no es otra cosa que una infracción que ha sido previamente "castigada" por alguna de las sanciones contenidas en el artículo 38 de la LOSMA, que reúne alguno de los criterios de magnitud, gravedad, reiteración o efectos, podrá iniciarse un proceso sancionatorio asociado a la comisión de infracciones graves o gravísimas, de acuerdo con el artículo 36 de la LOSMA, en el cual existirá la posibilidad de imponer como sanción la revocación de la RCA, la que produce el mismo efecto extintivo que la declaración de caducidad. En otras palabras, si un titular de un proyecto ha sido ya sancionado por la SMA, y comete nuevamente una infracción, de gran magnitud, alta gravedad o nocivos efectos para el medio ambiente, tal incumplimiento podrá subsumirse bajo las hipótesis de infracciones

33 Por ejemplo, en el caso del recurso de protección, aun cuando no se trata de un proceso cautelar como lo ha constatado Bordalí Salamanca, A., "Diversos significados de la tutela cautelar en el proceso civil", en Revista de Derecho (Valdivia), Vol. 12, No 2, 2001, p. 65, es posible adoptar "medidas cautelares en su sentido más tradicional”, como la suspensión o una orden de no innovar. Al respecto, véase también, en una perspectiva procesal, Tavolari Oliveros, R., "La Orden de no Innovar en el Recurso de Protección (Una Manifestación de la Tutela Cautelar en Derecho Chileno)", en Justicia III, No I, 1992, pp. 685-715. En una perspectiva propiamente administrativa, véase Oelckers Camus, O., "La suspensión de los efectos del acto administrativo debido a la orden de no innovar", en Revista de Derecho, Pontificia Universidad Católica de Valparaíso, vol. XVI, Valparaíso, 1995, p. 326. 
graves y gravísimas, las que pueden sancionarse con revocación de la RCA. Por ello, es inútil además considerar una sanción adicional, que genera los mismos efectos extintivos, como la caducidad de la RCA.

En segundo lugar, dicho supuesto podría significar la imposición, eventualmente, de una doble sanción por un mismo hecho, cuestión que desde luego podría vulnerar el principio de non bis in idem y, de forma consecuente, el principio de culpabilidad. En efecto, la eventual caducidad que se declare, habiéndose previamente comprobado y sancionado determinadas infracciones de acuerdo con el catálogo previsto por el artículo 38 de la LOSMA, podría implicar una afectación al principio de culpabilidad, toda vez que existiría un juicio de reprochabilidad adicional por un hecho que ya fue objeto de una sanción administrativa, infringiendo, particularmente, su dimensión cualitativa (componente subjetivo) al castigar nuevamente un supuesto sin que este hubiere estado dentro de las posibilidades de previsión al momento de actuar ${ }^{34}$. De la misma manera, si la RCA de un proyecto o actividad es objeto, previamente, de un proceso sancionatorio ambiental en atención a determinadas infracciones "comprobadas", la declaración posterior de caducidad de la RCA podría importar una nueva sanción por los mismos hechos, esto es, aquellos revestidos de cuatro criterios de imposición (magnitud, gravedad, reiteración o efectos).

\section{2. Órgano que detenta la potestad de caducar una RCA}

La determinación del órgano competente para declarar la caducidad de la RCA no constituye una materia de feliz desarrollo en la Ley $\mathrm{N}^{\circ} 20.417$. En efecto, como hemos visto, la Ley solo se refirió a la existencia de la caducidad general al modificar el artículo 25 ter de la Ley $N^{\circ} 19.300$, señalando posteriormente que la SMA podrá requerir del SEA la declaración de caducidad en los casos que indica. Hasta ahí, no era suficientemente claro si la caducidad debía declararla la SMA o el SEA. Sin embargo, el artículo 73 del Reglamento del SEIA otorgó la facultad de declarar tal caducidad al SEA, estableciendo que corresponderá a la Superintendencia constatar lo anterior qque bubieren transcurrido más de cinco años sin que se haya iniciado la ejecución del proyecto o actividad autorizada, contados desde su autorizaciónt y requerir al Servicio que declare dicha caducidad.

De acuerdo con lo anterior, al menos respecto de la caducidad general, la ley y más claramente el Reglamento, entregaron al SEA la facultad de declarar la caducidad, lo que notoriamente constituye una impropiedad en cuanto al diseño de la nueva institucionalidad ambiental dispuesto por la Ley No 20.417. Así, cabe preguntarse, ¿por qué se entrega al SEA la facultad para caducar una RCA en circunstancias que la Ley N ${ }^{\circ} 19.300$ le atribuyó potestades para administrar el SEIA -que dicho sea de paso no fue hecho

${ }^{34}$ Véase Alarcón Sotomayor, L., "Principio Non Bis In Ídem”, en Diccionario de Sanciones Administrativas (Dir. Blanca Lozano Cutanda), Iustel, Tomo I, Madrid, 2010, p. 762. Igualmente, Véase De Palma del Teso, A., "Principio de Culpabilidad: Definición y Aplicación a las Personas Físicas, en Diccionario de Sanciones Administrativas (Dir. Blanca Lozano Cutanda), Iustel, Tomo I, Madrid, 2010, p. 702. 
para rechazar proyectos, sino que para aprobarlos, incluso condicionadamente ${ }^{35}-\mathrm{y}$ también para calificar ambientalmente proyectos o actividades? De la forma en que está concebida, no es posible entender la finalidad de la atribución de la comentada potestad al SEA, el cual constituye un organismo que califica ambientalmente proyectos y que carece, por cierto, de potestades fiscalizadoras y sancionadoras, salvo las dispuestas en el artículo único de la Ley $\mathrm{N}^{\circ} 20.473$, para el tiempo intermedio en que comenzaba el funcionamiento de la SMA.

Pero no solo por el hecho de que el SEA carezca de potestades sancionadoras es cuestionable que se le entregue la facultad de caducar una RCA. También lo es porque las facultades relacionadas con la ejecución de obras para materializar las distintas fases de un proyecto o actividad están directamente vinculadas con la "fiscalización y seguimiento ambiental", que corresponde a la SMA, según lo dispuesto en el artículo 3 letra a) de su Ley Orgánica. De hecho, el mismo artículo 73 del Reglamento del SEIA, en su inciso final, establece que el titular deberá informar a la Superintendencia la realización de la gestión, acto o faena mínima que dé cuenta del inicio de la ejecución de obras. Entonces, ¿por qué razón se entrega la facultad en comento al SEA, si su actividad se agota con la calificación ambiental y, eventualmente, con sus posteriores modificaciones?, si es el SEA el encargado de la declaración de caducidad, ¿qué ocurrirá si en dicho procedimiento, el de declaración, el SEA no comparte el criterio de constatación de la SMA?, ¿está igualmente obligado a declararla? Sin duda se trata de un asunto más colmado de dudas que de certezas.

Ahora bien, el asunto es más complejo de determinar en el caso de la caducidad sanción, pues si bien el artículo 73 del Reglamento entrega la facultad de caducar la RCA al SEA, lo hace solo respecto de la no ejecución del proyecto en el plazo legal, sin señalar nada con relación a qué órgano le corresponde declarar la caducidad sanción.

En nuestra opinión, tratándose de un asunto directamente vinculado con el seguimiento ambiental y, particularmente, de un supuesto asociado a una infracción previa, y en razón de constituir una verdadera sanción administrativa que ha modificado el catálogo punitivo contenido en el artículo 38 de la LOSMA, estimamos que la declaración de caducidad sanción corresponde a la SMA, previo informe del SEA. Ello es importante, particularmente en lo que dice relación con el procedimiento administrativo (sancionatorio) que debe generarse para declarar la caducidad de la RCA y con los eventuales recursos administrativos y jurisdiccionales que nacen para el titular responsable del proyecto o actividad y los demás interesados.

Por último, bajo ambos supuestos de caducidad, debió entregarse la potestad respectiva derechamente a la SMA, requiriendo para el ejercicio de la misma el informe respectivo del SEA. Lo anterior, por cuanto la caducidad, en la forma que ha sido establecida por la ley ambiental, constituye prácticamente una sanción administrativa -ya sea propia

35 Astorga Jorquera, E., Derecho Ambiental Chileno, Editorial LexisNexis, Segunda edición, Santiago, 2007, p. 223. El mismo autor también en Derecho Ambiental Chileno Parte General, Editorial LegalPublishing, Tercera edición actualizada, Santiago, 2012, p. 189. 
o impropia como hemos sostenido más arriba-, que incluso genera los mismos efectos extintivos de una revocación de la RCA.

\subsection{Procedimiento aplicable}

El procedimiento para determinar la caducidad de una RCA constituye un asunto de la mayor importancia, ya que la garantía de un racional y justo procedimiento es un derecho fundamental básico y un "principio esencial para la vigencia del Estado de Derecho que debe ser respetada por el legislador y por el juez y que debe estar presente en todo procedimiento que contemple la ley"36. A continuación nos referimos a algunos de los aspectos esenciales omitidos por la ley, asociados al procedimiento administrativo que debe seguirse para la declaración de caducidad en sus dos modalidades.

\section{(a) Naturaleza del procedimiento}

La declaración de caducidad requiere, en cualquiera de sus supuestos, el inicio e instrucción de un procedimiento administrativo, cuya naturaleza específica será diversa dependiendo del tipo de caducidad de que se trate.

Así, en el caso de la caducidad general, en la medida que a su respecto las garantías procedimentales fueron simplemente omitidas por la Ley $\mathrm{N}^{\circ} 20.417$, será la Administración la llamada a suplir tal vacío, tanto la SMA como el SEA, mediante la aplicación supletoria de la Ley $\mathrm{N}^{\circ}$ 19.880. Por su parte, en el caso de la caducidad sanción, que como dijimos constituye una verdadera sanción administrativa, deberá ser precedida del respectivo procedimiento sancionatorio, de acuerdo con el artículo 47 y siguientes de la LOSMA, los que contienen los trámites y diligencias generales que la SMA debe respetar en esa clase de procedimientos.

\section{(b) Legitimación activa e inicio del procedimiento}

En el caso de la caducidad general, la legitimación activa posee un carácter amplio, porque cualquier persona podrá solicitar a la SMA que determine si, en su concepto, se cumplen los requisitos para la aplicación de tal figura y, en caso afirmativo, para que dicho organismo requiera al SEA la declaración respectiva. Por su parte, respecto de la caducidad sanción, el procedimiento sancionatorio podrá iniciarse de oficio por la SMA, a petición de un órgano sectorial, o por denuncia, según lo establece el artículo 47 de la LOSMA.

Ahora bien, un escenario interesante se genera respecto del inicio de procedimiento mediante denuncias. En efecto, como es sabido, el artículo 21 de la LOSMA permite que cualquier persona denuncie ante la SMA el incumplimiento de instrumentos de gestión

${ }^{36}$ Véase Vargas Delgado, I., "La garantía del justo y racional procedimiento en la jurisdicción tributaria", en Revista Chilena de Derecho, Vol. 25 No 3, 1998, p. 549. 
ambiental y normas ambientales, debiendo dicho organismo informar sobre los resultados de su denuncia en un plazo no superior a 60 días hábiles. Así, cualquier persona que estime incumplido un instrumento de gestión ambiental o determinadas normas ambientales, de seguirse un procedimiento administrativo sancionatorio, tendrá la calidad de interesado en el precitado procedimiento. Lo anterior no es un asunto trivial, ya que al habérsele reconocido la calidad de interesado, desde luego podrá recurrir, eventualmente, ante el Tribunal Ambiental si de alguna manera la resolución de término le irroga perjuicios ${ }^{37}$.

\section{(c) Solicitud de informes}

Una vez iniciado el procedimiento asociado a la caducidad general, y como lo permite el artículo 37 de la Ley $\mathrm{N}^{\circ} 19.880$, la SMA podrá solicitar los informes que estime pertinentes, que den cuenta del estado actual de materialización del proyecto o actividad autorizada. Igualmente, el SEA, una vez requerido por la SMA, podrá solicitar los informes que le permitan ser ilustrado adecuadamente sobre los hechos influyentes o pertinentes a los fines del proceso, o sobre los hechos dudosos o controvertidos, y le sirvan de fundamento a la decisión final sobre la caducidad ${ }^{38}$. Así, por ejemplo, se podrán requerir de las Direcciones de Obras Municipales del área de influencia del proyecto o actividad autorizada, que se informe acerca de los permisos de construcción, reparación, alteración, ampliación y demolición de edificios y obras de urbanización de cualquier naturaleza que pudieran dar cuenta de realización de actos materiales asociados al inicio de la ejecución del proyecto.

De la misma manera, tratándose de un procedimiento sancionatorio asociado a la caducidad sanción, la SMA podrá también requerir informes de otros organismos sectoriales con competencia ambiental, a fin de determinar la procedencia de declarar la caducidad,

${ }^{37}$ En este sentido, el Segundo Tribunal Ambiental de Santiago, mediante la sentencia de 3 de marzo de 2014, recaída en la causa Rol R 6-2013, fijó un criterio al establecer que la legitimación ambiental está directamente relacionada con el concepto de "área de influencia del proyecto". Así, una persona que, habiendo presentado observaciones ciudadanas en el marco de la evaluación ambiental de una DIA o EIA, de acuerdo con los artículos 29 y 30 bis de la Ley $\mathrm{N}^{\circ} 19.300$, estime que el proyecto o actividad -que está inserto en su área de influencia- no ha dado inicio de ejecución al mismo, mediante la materialización de sus respectivas obras, puede denunciar ante la SMA y requerir del SEA la declaración de caducidad. Todo ello, eso sí, en la medida que la falta de ejecución o materialización de las obras del proyecto le generen algún perjuicio, es decir, tenga la calidad de directamente afectado. A su vez, la calidad de directamente afectado exige un "interés", el que no puede estar limitado por uno simplemente de carácter patrimonial, sino también aquel que comprenda consideraciones de naturaleza ambiental. Sobre el concepto de interés puede verse el reciente trabajo de Ferrada Bórquez, J.C., "La legitimación activa de los procesos administrativos anulatorios", en $L a$ Nulidad de los Actos Administrativos en el Derecho Chileno. IX Jornadas de Derecho Administrativo, Juan Carlos Ferrada Bórquez (Coordinador), Editorial Thomson Reuters, Santiago, 2013, pp. 157-187.

38 Sobre los requisitos para ser admitidos determinados informes como prueba en el procedimiento administrativo, véase González Pérez, J., Manual de Derecho Procesal Administrativo, Civitas, Tercera edición, Madrid, 2001, p. 329-330. Igualmente, Cosculluela Montaner, L., Manual de Derecho Administrativo Parte General, Civitas Thomson Reuters, Vigésimo tercera edición, Pamplona, 2012, p. 364. 
tendientes a acreditar la concurrencia de los criterios de magnitud, gravedad, reiteración o efectos de la infracción comprobada, en los términos del artículo 52 de la LOSMA.

Por último, es importante recordar que estos informes no tienen el carácter de vinculantes, toda vez que la ley ambiental nada dice al respecto y por lo tanto la aplicación supletoria del artículo 38 de la Ley $\mathrm{N}^{\circ} 19.880$, que establece que salvo norma expresa en contrario los informes serán facultativos y no vinculantes, se hace efectiva.

(d) Plazo para resolver el procedimiento

Tanto en el caso de la caducidad general como en el de la caducidad sanción la ley no prevé un plazo para que, por una parte, la SMA tramite el procedimiento respectivo, ni tampoco para que el SEA proceda a la declaración de caducidad por la correspondiente resolución cuando le corresponda. Así las cosas, se deben considerar supletoriamente el artículo 27 de la Ley $\mathrm{N}^{\circ}$ 19.880, que establece que el procedimiento administrativo, salvo caso fortuito o fuerza mayor, no podrá exceder de 6 meses, desde su iniciación hasta la fecha en que se emita la decisión final. Sin embargo, dicho plazo para terminar el procedimiento mediante la resolución final es meramente hipotético, toda vez que conforme ha resuelto la Contraloría de forma reiterada, los plazos que rigen a la Administración no poseen el carácter de fatales ${ }^{39}$.

\section{(e) Resolución que caduca la RCA}

El procedimiento iniciado con motivo de una caducidad general deberá culminar con una resolución administrativa del SEA, que naturalmente deberá cumplir con el estándar de motivación exigido por la Ley $\mathrm{N}^{\circ} 19.880$, esto es, que se expresen las razones de hecho y de derecho que determinaron la decisión ${ }^{40}$. El estándar de motivación se cumple en tanto se acredite la omisión en la que ha incurrido el responsable del proyecto o actividad autorizada durante el término de 5 años respecto de la inejecución de las obras, partes o acciones consideradas en la descripción del respectivo proyecto.

En el caso de la caducidad sanción, el proceso sancionatorio deberá culminar también con una resolución fundada, en la que se absolverá al infractor o se le aplicará la sanción de caducidad, según lo exige el artículo 54 de la LOSMA. Ahora bien, tratándose de esta segunda modalidad de caducidad el asunto es más complejo, toda vez que la ley no establece criterios ni límites para su determinación, ya que únicamente se refiere a la existencia de infracciones comprobadas (castigadas) previamente, que sean revestidas de los parámetros que hemos comentado (magnitud, gravedad, reiteración o efectos).

Por lo tanto, en este último caso, la SMA, mediante un ejercicio interpretativo previo, deberá acreditar que debido a la magnitud, gravedad, reiteración o efectos es procedente

${ }^{39}$ Entre otros los dictámenes Nos 77.444 , de fecha 13 de diciembre de 2012, No 34.291 , de fecha 27

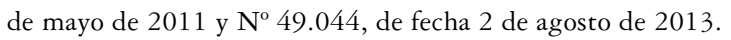

${ }^{40} \mathrm{Al}$ respecto, véase Aróstica Maldonado, I., "La motivación de los actos administrativos en el derecho chileno”, en Revista de Derecho, Pontificia Universidad Católica de Valparaíso, Vol. X, 1986, p. 500. 
jurídicamente caducar la RCA. Para ello, desde luego deberá quedar constancia en la resolución respectiva de: (i) de todos los procesos sancionatorios incoados en contra de la RCA del responsable del proyecto; (ii) de las sanciones impuestas y eventualmente de los comprobantes de pagos de las mismas o de los programas de cumplimiento asumidos; (iii) el señalamiento de los hechos que eventualmente pueden importar la reiteración o reincidencia de infracciones a una misma autorización de funcionamiento; (iv) la descripción de las consecuencias dañosas para el medio ambiente o la salud de la población, susceptible o no de reparación, entre otras.

\section{(f) Notificación o publicación}

En el caso de la caducidad general, dependiendo del caso concreto, la resolución final deberá ser notificada o publicada. En tanto el proyecto o actividad autorizada no afectare a personas cuyo paradero fuere ignorado o que interese a un número indeterminado de personas, la resolución simplemente será notificada por escrito, mediante carta certificada dirigida al domicilio de los respectivos interesados, siendo esta la forma más común de notificación. Igualmente se debiera notificar, además, al conjunto de órganos de la Administración del Estado que participaron de la evaluación ambiental del respectivo proyecto o actividad o que otorgaron los respectivos permisos ambientales sectoriales, para que conozcan la circunstancia de haberse caducado la RCA.

De la misma manera, la notificación que absuelva al presunto infractor en el marco del procedimiento sancionatorio deberá ser notificada por la SMA por escrito, generalmente mediante carta certificada dirigida al domicilio del respectivo interesado.

\subsection{Efectos de la declaración de caducidad de la RCA}

Como ya hemos dicho, la declaración de caducidad general o la aplicación de la caducidad sanción, generan la extinción del título habilitante para la ejecución del proyecto o actividad originalmente autorizado. Por lo tanto, la declaración de caducidad importará la necesidad de someter nuevamente el proyecto o actividad al SEIA, y así obtener nuevamente un título administrativo que permita desarrollarlo con arreglo a la ley. En definitiva, declarada la caducidad o impuesta como sanción, el responsable del proyecto no podrá ejecutarlo en los términos originalmente autorizados, por haber desaparecido consecuencialmente del ordenamiento jurídico el título otorgado.

\subsection{Recursos que proceden contra la resolución que caduque la RCA}

En términos generales, cualquier interesado, ya sean las personas naturales o jurídicas directamente afectadas por la construcción del proyecto o actividad, o el responsable del mismo, pueden estimar que con la decisión, la autoridad ambiental afectó o perjudicó sus intereses o derechos. Bajo esa lógica, los actos que al efecto se dicten siempre serán impugnables, como todo otro acto administrativo de contenido ambiental, mediante los recursos administrativos o contencioso-administrativos que garantizan los derechos e 
intereses de los afectados con la decisión final ${ }^{41}$, y permiten un control interno y externo de la actividad administrativa ${ }^{42}$.

En ese contexto, la impugnación de la resolución que declare la caducidad constituye una cuestión de la mayor relevancia, no obstante ello presenta un doble y desigual tratamiento, según se trate de la declaración de caducidad general o la aplicación de la misma como sanción.

Así, tratándose de la declaración de caducidad general, efectuada por el SEA, la resolución que la disponga únicamente es susceptible de ser controvertida en sede administrativa mediante la presentación de una solicitud de invalidación ante el mismo órgano que la dictó, según lo dispuesto en el artículo 53 de la Ley $\mathrm{N}^{\circ} 19.880$, sin perjuicio de la eventual interposición de un recurso de reposición. El supuesto fundamental de la solicitud de invalidación descansará en la existencia de un acto contrario a derecho que, en el presente caso, estaría dado por la infracción de lo dispuesto en el artículo 25 ter de la Ley $\mathrm{N}^{0} 19.300$, en cuanto al cómputo del plazo o a la existencia de gestiones, actos u obras que dan cuenta, de forma efectiva, de la materialización de la fase de construcción de un proyecto o actividad autorizada.

En esta hipótesis, desde el punto de vista jurisdiccional, la ley no contempla una acción directa para recurrir ante el Tribunal Ambiental contra la eventual resolución del SEA que declare la caducidad, siendo la única vía para acceder a tal Tribunal reclamar contra la resolución que resuelva la invalidación, de acuerdo con el numeral 8 del artículo 17 de la Ley No 20.600. Sin perjuicio de ello, siempre existirá el derecho de ejercer la acción de protección, en la medida que la declaración de caducidad importe un acto u omisión arbitrario o ilegal, que afecte derechos constitucionales (según el caso, las garantías de los números $2^{\circ}, 8^{\circ}, 21^{\circ}$ y $24^{\circ}$, sin perjuicio de otras).

Por su parte, la resolución por la cual la SMA aplique la caducidad sanción será susceptible de ser impugnada mediante la correspondiente reposición, como lo dispone el artículo 55 de la LOSMA, sin perjuicio de la eventual reclamación contenciosoadministrativa ante el Tribunal Ambiental, según el artículo 56 de la misma ley, en tanto se estime que la resolución de la SMA no se ajusta a derecho.

Como se puede observar, en materia de recursos se presenta una gran diferencia entre ambas modalidades estudiadas, la que está dada por la inexistencia de acción directa de reclamación ante el Tribunal Ambiental en el caso de la caducidad general. En efecto, el diseño legal y reglamentario, en esa hipótesis, obliga al afectado a solicitar previamente una invalidación, la que naturalmente está sujeta al inicio e instrucción de un nuevo procedimiento administrativo, lo que dilata la posibilidad de acceder a la tutela judicial especializada.

${ }^{41}$ Bermúdez Soto, J., Op. Cit. (n. 34), p. 491 y siguientes.

42 Escuin Palop, V., y Belando Garín, B., Los recursos administrativos, Civitas, Pamplona, 2011, p. 42. Igualmente, Schmidt-Assmann, E., (n. 2), p. 381. En el mismo sentido, véase Ferrada Bórquez, J.C., "Los procesos administrativos en el Derecho chileno", en Revista de Derecho, Pontificia Universidad Católica de Valparaíso, vol. XXXVI, Valparaíso, 2011, p. 264. 
Al respecto, claramente existe una incongruencia en la materia, ya que el contenciosoadministrativo ambiental diseñado por la Ley $\mathrm{N}^{\circ} 20.417$ y la Ley $\mathrm{N}^{\circ} 20.600$ descansa sobre el otorgamiento de una tutela judicial directa respecto de actos administrativos ambientales de gravamen que irroguen grave perjuicio a los interesados, como ocurre tratándose de cualquier sanción administrativa aplicada por la SMA. Así, de acuerdo con el diseño actual, mientras la aplicación de una sanción de revocación de RCA puede ser derechamente reclamada ante el Tribunal Ambiental, una declaración de caducidad general efectuada por el SEA, la que genera el mismo efecto extintivo del acto autorizatorio, no puede serlo directamente.

\section{COMENTARios FinAlES}

En estas páginas hemos podido conocer los alcances de la caducidad en materia medioambiental, previa conceptualización desde el Derecho civil y administrativo. En este sentido, si bien creemos que el establecimiento de la caducidad general resulta plausible como una forma adicional de extinción de la RCA, no estimamos lo mismo en el caso de la caducidad sanción, ya que aquella ha sido configurada como una herramienta carente de utilidad y de dudosa constitucionalidad, pues dependiendo de las circunstancias particulares de cada caso su aplicación podría infringir el principio non bis in idem. Es de esperar que el uso de esta técnica administrativa extintiva de los actos autorizatorios ambientales, particularmente en el caso de la caducidad sanción, sea efectuada bajo criterios de razonabilidad y proporcionalidad, atendida la deficiente regulación normativa.

\section{BIBLIOGRAFÍA}

Abeliuk Manasevich, R., Las Obligaciones, Editorial Jurídica de Chile, Tomo II, Santiago, 2001, $1148 \mathrm{pp}$.

Alarcón Sotomayor, L., "Principio Non Bis In Ídem", en Diccionario de Sanciones Administrativas (Dir. Blanca Lozano Cutanda), Iustel, Tomo I, Madrid, 2010, pp. 762-779.

Alessandri, A. y Somarriva, M., Curso de Derecho Civil, Tomo I, Volumen II: Parte General y Las Personas, Editorial Nascimiento, Santiago, 1962, 397 pp.

Aróstica Maldonado, I., "La motivación de los actos administrativos en el derecho chileno", en Revista de Derecho, Pontificia Universidad Católica de Valparaíso, Vol. X, 1986, pp. 499-520.

Astorga Jorquera, E., Derecho Ambiental Chileno, Editorial LexisNexis, Segunda edición, Santiago, 2007, 385 pp.

Astorga Jorquera, E., Derecho Ambiental Chileno Parte General, Editorial LegalPublishing, Tercera edición actualizada, Santiago, 2012, 402 pp.

Bermúdez Soto, J., Fundamentos de Derecho Ambiental, Ediciones Universitarias de Valparaíso, 2007, $285 \mathrm{pp}$

Bermúdez Soto, J., Derecho Administrativo General, Legal Publishing Chile, Santiago, 2011, 603 pp.

BERMúdez Soto, J., "Administración y Jurisdicción Ambiental: La institucionalidad ambiental frente al nuevo contencioso-administrativo”, en La Nulidad de los Actos Administrativos en 
el Derecho Chileno. IX Jornadas de Derecho Administrativo, Juan Carlos Ferrada Bórquez (coordinador), Editorial Thomson Reuters, Chile, pp. 485-511.

Bordalí Salamanca, A., "Diversos significados de la tutela cautelar en el proceso civil", en Revista

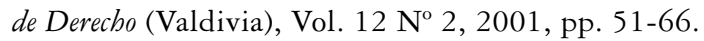

Caballero Sánchez, R. "Procedimiento Sancionador: Caducidad", en Diccionario de Sanciones Administrativas (Dir. Blanca Lozano Cutanda), Iustel, Primera edición, Madrid, 2010, pp. 799-826.

Carmona Santander, C., Las Formas de Actuación de la Administración. El Acto Administrativo, Facultad de Derecho de la Universidad de Chile, Santiago, 2005, 135 pp.

Cordero Vega, L., "El Decaimiento del Procedimiento Administrativo Sancionador", en Comentarios a las Sentencias de la Corte Suprema del año 2010, Anuario de Derecho Público, Universidad Diego Portales, Santiago, 2011, pp. 243-255.

Cosculluela Montaner, L., Manual de Derecho Administrativo Parte General, Civitas Thomson Reuters, Vigésimo tercera edición, Pamplona, 2012, 682 pp.

De Diego Díez, L.A., Prescripción y Caducidad en el Derecho Administrativo Sancionador, Bosch, Barcelona, 2005, 292 pp.

De la Fuente Castro, O., El control judicial de la resolución de calificación ambiental, LegalPublishing, Santiago, 2012, $152 \mathrm{pp}$.

De Palma del Teso, A., "Principio de Culpabilidad: Definición y Aplicación a las Personas Físicas”, en Diccionario de Sanciones Administrativas (Dir. Blanca Lozano Cutanda), Iustel, Tomo I, Madrid, 2010, pp. 702-721.

Desdentado Daroca, E., "Discrecionalidad Administrativa en la Imposición de Sanciones", en Diccionario de Sanciones Administrativas (Dir. Blanca Lozano Cutanda), Iustel, primera edición, Madrid, 2010, pp. 345-349.

Domínguez Águila, R., La prescripción extintiva. Doctrina y jurisprudencia (Editorial Jurídica de Chile, 2004), 436 pp.

Escuin Palop, V., y Belando Garín, B., Los recursos administrativos, Civitas, Pamplona, 2011, 506 pp.

Ferrada Bórquez, J.C., "La legitimación activa de los procesos administrativos anulatorios", en La Nulidad de los Actos Administrativos en el Derecho Chileno. IX Jornadas de Derecho Administrativo, Juan Carlos Ferrada Bórquez (coordinador), Editorial Thomson Reuters, Santiago, 2013, pp. 157-187.

Ferrada Bórquez, J.C., "Los procesos administrativos en el Derecho chileno", en Revista de Derecho, Pontificia Universidad Católica de Valparaíso, vol. XXXVI, Valparaíso, 2011, pp. 251-277.

García DE Enterría, E. y Fernández, T., Curso de Derecho Administrativo. II, Civitas, Duodécima edición, Pamplona, 2011, 767 pp.

Gómez Corraliza, B., La Caducidad, Editorial Montecorvo S.A., Madrid, 1990, 655 p.

GonzÁlez Pérez, J., Manual de Derecho Procesal Administrativo, Civitas, Tercera edición, Madrid, 2001, 724 pp.

González Pérez, J., y González Navarro, F., Comentarios a la Ley de Régimen Jurídico de las Administraciones Públicas y Procedimiento Administrativo Común, Civitas, Madrid, 2004, 3691 pp.

Laguna de Paz, J., La Autorización Administrativa, Editorial Aranzadi, Navarra, 2006, 377 pp.

Oelckers Camus, O., "La suspensión de los efectos del acto administrativo debido a la orden de no innovar", en Revista de Derecho, Pontificia Universidad Católica de Valparaíso, vol. XVI, Valparaíso, 1995, pp. 323-331.

Olguín Juárez, H., Extinción de los Actos Administrativos. Revocación, Invalidación y Decaimiento, Editorial Jurídica de Chile, Santiago, 1961, 293 pp.

Parejo Alfonso, L., Lecciones de Derecho Administrativo, Editorial Tirant lo Blanch, Quinta edición revisada y actualizada, Valencia, 2012, 990 pp. 
Rodríguez Arana, J., "Reflexiones Sobre la Caducidad en el Derecho Público", en Revista Aragonesa de Administración Pública, Zaragoza, No 5, 1994, pp. 340-355.

Santamaría Pastor, J.A., Principios de Derecho Administrativo General, Tomo II, Iustel, Madrid, 2009, 790 pp.

Schimdt-Assman, E., La Teoría General del Derecho Administrativo como Sistema, Marcial Pons, Barcelona, 2003, 475 pp.

Soto Kloss, E. "Prescripción extintiva de derechos de los administrados y cumplimiento de las obligaciones legales impuestas a la Administración”, en Revista Chilena de Derecho, Vol. 11, $\mathrm{N}^{\circ}$ 2-3, 1984, pp. 505-518.

TArdío Pato, J.A., "Caducidad del procedimiento administrativo", en Diccionario de Derecho Administrativo (Dir. Santiago Muñoz Machado), Iustel, Tomo I, Madrid, 2005, 358-366 pp.

Tardío Pato, J.A., "Consideraciones Sobre la Caducidad del Procedimiento Administrativo", en Revista de Estudios de la Administración Local y Autonómica, No 298-299, 2005, pp. 11-53.

TAvolari Oliveros, R., "La orden de no innovar en el recurso de protección (una manifestación de la tutela cautelar en derecho chileno)", en Justicia III, No I, 1992, pp. 685-715.

VARGas Delgado, I., "La garantía del justo y racional procedimiento en la jurisdicción tributaria", en Revista Chilena de Derecho, Vol. 25 No 3, 1998, pp. 549-563.

Vergara Blanco, A., "Nota sobre la caducidad como fuente de extinción de derechos y del decaimiento del procedimiento administrativo", en Actas XXXIV Jornadas de Derecho Público Pontificia Universidad Católica de Chile, Santiago, 2004, pp. 567-572.

Wahl, R., Los Últimos Cincuenta Años de Derecho Administrativo Alemán, Marcial Pons, Madrid, 2013 , pp. 167. 